\title{
A new method of measuring the thumb pronation and palmar abduction angles during opposition movement using a three-axis gyroscope
}

\author{
Tomoyuki Kuroiwa', Koji Fujita ${ }^{1 *}$ D, Akimoto Nimura ${ }^{2}$, Takashi Miyamoto², Toru Sasaki ${ }^{1}$ and Atsushi Okawa ${ }^{1}$
}

\begin{abstract}
Background: Thumb opposition is vital for hand function and involves pronation and palmar abduction. The improvement of pronation is often used as one of the evaluation items of the opponensplasty method for severe carpal tunnel syndrome. However, most of the studies used substitution evaluation methods for measurement of the pronation angle. Thus, there is still no appropriate method for measuring thumb pronation angle accurately in carpal tunnel syndrome patients.

In recent reports, a wearable gyroscope was used to evaluate upper extremity motions and it can be possibly used for accurate measurement of the thumb pronation angle along the three-dimensionally moving bone axis.

Thus, we investigated the reliability of measuring thumb pronation using a gyroscope and evaluated whether this method can be used to detect opposition impairment.
\end{abstract}

Methods: The participants were volunteers with unaffected upper limbs (32 hands) and patients with carpal tunnel syndrome (27 hands). The pronation and palmar abduction angles during opposition movements were measured using a three-axis gyroscope that included a three-axis accelerometer. The gyroscope was fixed onto the first metacarpal bone and the thumb phalanx.

Results: The pronation and palmar abduction angles of the metacarpal bone and the palmar abduction angles of the phalanx significantly decreased in the carpal tunnel syndrome group. The pronation angle of the metacarpal bone during opposition movement peaked later than the palmar abduction angle in all hands.

Conclusions: We were able to measure the thumb pronation and palmar abduction angles using the three-axis gyroscope, and this tool was able to detect impairments of thumb opposition due to carpal tunnel syndrome. This could be a tool for measuring thumb and finger angles and for detecting impairments caused by various diseases.

Keywords: Gyroscope, Motion analysis, Thumb opposition, Thumb pronation, Carpal tunnel syndrome

\section{Background}

The thumb is vitally important for hand function and accounts for $40-50 \%$ of hand function [1-5]. The most significant factor contributor to the hand's function is opposition [6, 7]. Opposition movement plays a key role in hand motions such as pulp pinch, grip, and

\footnotetext{
* Correspondence: fujiorth@tmd.ac.jp; fujita.orth@tmd.ac.jp

${ }^{1}$ Department of Orthopaedic and Spinal Surgery, Graduate School of Medical and Dental Sciences, Tokyo Medical and Dental University, 1-4-5, Yushima, Bunkyo-ku, Tokyo 113-8519, Japan

Full list of author information is available at the end of the article
}

grasp [2, 8-10]. Thumb opposition movement includes two elements, namely, pronation and palmar abduction $[1,11,12]$. Of these, pronation is essential for grasp and pulp pinch [13]. Carpal tunnel syndrome (CTS) is a disease that causes weakness of the thumb's muscle because of thenar atrophy, resulting in opposition impairment $[11,14-16]$. Hence, the extent of improvement in pronation was often used as one of the evaluation items of the opponensplasty method which is aimed to regain the opposition function equivalent to that of healthy subjects [13,17-21]. Nevertheless, in

(c) The Author(s). 2018 Open Access This article is distributed under the terms of the Creative Commons Attribution 4.0 International License (http://creativecommons.org/licenses/by/4.0/), which permits unrestricted use, distribution, and reproduction in any medium, provided you give appropriate credit to the original author(s) and the source, provide a link to the Creative Commons license, and indicate if changes were made. The Creative Commons Public Domain Dedication waiver (http://creativecommons.org/publicdomain/zero/1.0/) applies to the data made available in this article, unless otherwise stated. 
these reports, nail tip angle, spatial angle, or Kapandji score were used in the substitution evaluation method for the measurement of the pronation angle. Indeed, these methods can be adapted longitudinal evaluation of a single patient; however, they have a number of shortcomings. The first two are not three-dimensional evaluation methods, and the last one is not an accurate quantitative evaluation method but is a numerical categorized method; therefore, even if thenar atrophy increases because of increasing severity, it does not reflect clearly in the numerical value [22]. Thus, despite the decrease in the pronation of the thumb in CTS patients in actual clinical practice, the lack of an appropriate assessment method to evaluate the patients' function remains.

Various motion analyses of the lower extremities using a gyroscope and accelerometer have been reported [23-26]. In some recent reports, a gyroscope was used to evaluate upper extremity motions in patients with neuromuscular disorders, such as Parkinson's disease [27, 28] or Duchenne muscular dystrophy [29]. A gyroscope is small, wearable, and easy to handle $[30,31]$; hence, we hypothesized that we could measure the thumb pronation angle along the three-dimensionally moving bone axis using a gyroscope.

Therefore, we devised a method for measuring the angles of thumb pronation using a gyroscope and measured the angles in volunteers and patients with CTS during opposition movements. The purposes of this study were to investigate the reliability of measuring thumb pronation using a gyroscope and to evaluate whether this method can be used to detect opposition impairments.

\section{Methods}

This comparative study to investigate the validity of measuring thumb pronation using a new sensor was approved by the institutional review board of our institution, and all participants provided written informed consent.

\section{Participants}

We recruited 16 patients with CTS and thenar atrophy before surgery (CTS group, 27 hands) and 16 healthy volunteers (control group, 32 hands) between June 2017 and June 2018. Upon recruitment, we obtained information from the patients regarding their chief complaint and the trauma history of their hands. We performed medical interview and physical examination such as CTS induction tests and took X-ray images of the hands of all patients.

As the CTS group, patients were included if they were primarily diagnosed with CTS and planned to undergo carpal tunnel release. The diagnostic criteria for primary CTS included finger numbness; the physical findings of CTS, such as Tinel's sign or positive results on a compression test and the Phalen test; and an abnormal nerve conduction velocity (NCV) value, based on Padua's classification [32]. We excluded patients with a history of hand surgery or injury, recurrence after carpal tunnel release, positive physical and imaging findings indicative of first carpometacarpal (CM) or thumb metacarpophalangeal (MP) osteoarthritis that could affect the motion of thumb, suspicion of cervical spine disease, or positive magnetic resonance imaging findings of compression because of a space-occupying lesion.

As the control group, volunteers were included if they had undergone total hip arthroplasty in our hospital and if their age and sex matched those of patients in the CTS group. We excluded patients from the control group if they had a history of wrist, hand, or finger surgery or injury; thumb pain; finger numbness; positive physical findings of CTS; or positive imaging findings of osteoarthritis of the first CM or thumb MP. The reason for recruiting patients who underwent total hip arthroplasty for the control group was that these patients underwent routine X-ray of the hand preoperatively to assess the effect on $\mathrm{T}$ cane use; therefore, additional radiation exposure was unnecessary.

\section{Physical examination and NCV testing}

To diagnose CTS and evaluate the extent of impairment of thumb opposition, we obtained the following data before this study was performed. All physical findings were obtained through a physical examination by experienced hand surgeons. The degree of atrophy was evaluated in four stages with a visual inspection. The scores of a manual muscle test were evaluated using the Medical Research Council's Muscle Scale [33]. Experienced neurologists performed all $\mathrm{NCV}$ tests and evaluated these data.

\section{Apparatus}

The thumb's angular velocities and accelerations were measured using a three-axis gyroscope with a three-axis accelerometer (MP-M6-02/500C, angular velocity range $\pm 500 \%$ s; sampling rate $70 \mathrm{~Hz}$, acceleration range $\pm 20 \mathrm{~m} / \mathrm{s}^{2}$; sampling rate $200 \mathrm{~Hz}$, size $12 \mathrm{~mm}$ in width; $23 \mathrm{~mm}$ in depth; $5 \mathrm{~mm}$ in height, weight $3 \mathrm{~g}$, MicroStone, Nagano, Japan) during the participants' opposition movements. The gyroscope was fixed with tape at the dorsal side of the first metacarpal bone or on the middle of the thumb phalanx along the bone axis (Fig. 1a). The gyroscope was connected to a data logger (MVP-RF8, size $45 \mathrm{~mm}$ in width; $45 \mathrm{~mm}$ in depth; $18.5 \mathrm{~mm}$ in height, weight $60 \mathrm{~g}$, MicroStone). The accuracy of this data acquisition method was confirmed in a previous study using 


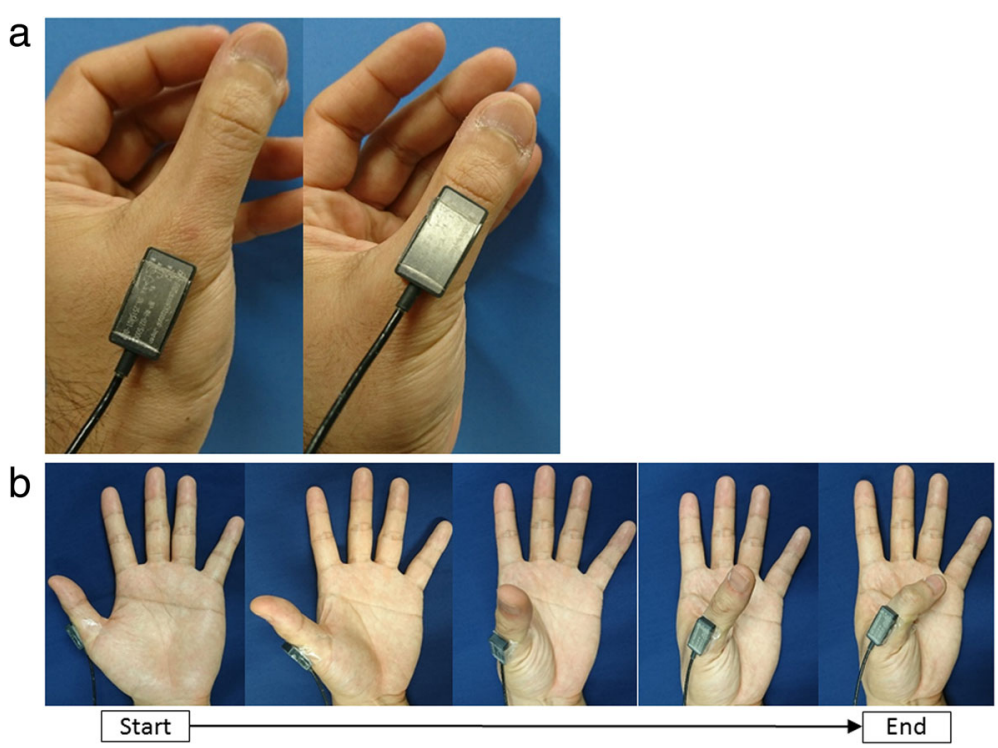

Fig. 1 The fixed position of the sensor and the opposition movement during measurement. a Left: the sensor on the metacarpal bone; right: on the phalanx along the bone axis. b Starting from abduction through full palmar abduction to flexion

the same type of sensor [34]. The gyroscope was calibrated statically against gravity before the measurements were made. The thumb's angular velocities and accelerations were sampled at $200 \mathrm{~Hz}$, and these signals were synchronized. After analog-to-digital transformation (10-bit resolution), the signals were collected in the logger and immediately transferred to a laptop PC (HP ProBook 450 G2, Hewlett-Packard, Boeblingen, Germany) via a Bluetooth Personal Area Network. It was possible to simultaneously measure the inclination angle of the horizontal plane and the rotation angles of the three axes, and these were calculated with data processing. The working range of the gyroscope to the PC was approximately $80 \mathrm{~cm}$. Signals were processed using commercially available software (MVP-DA2-S, MicroStone).

\section{Measurement}

Participants were instructed to oppose their thumb by drawing as large a semicircle as possible and to move their thumb five times in $45 \mathrm{~s}$. The angles of rotation and inclination of each bone axis were measured during five continuous reciprocating opposition movements, which were from the position of full radial abduction through full palmar abduction to full flexion of the MP and interphalangeal joints (Fig. 1b). These angles were first measured on the thumb phalanx and then on the metacarpal bone. During measurement, the examiner maintained the participant's wrist and MP joint of fingers in a stationary position.

We regarded the rotation angle as pronation/supination and the inclination angle as palmar abduction (Fig. 2). Angle data were evaluated using a system in which the direction of pronation and palmar abduction was considered positive. The difference between the maximum and minimum values was calculated for one opposition movement (Fig. 3). After excluding the first and last opposition movements from the five repeated measurements, we considered the average of these values as the range of motion during one opposition movement. Moreover, we evaluated which peak (pronation or palmar abduction) occurred earlier during one opposition movement.

\section{Statistical analysis}

Data regarding age and the motion angle are presented as the median with an interquartile range. The MannWhitney $U$ test was used to compare differences. A power analysis was performed on the basis of the pronation angles. To evaluate the intra-tester reliability, the standard deviation of three measurements was calculated for all trials, and the average value was calculated. Using the value, the coefficient of variation (CV) was also calculated. We performed all statistical analyses using EZR (EasyR, version 1.36). $P<0.05$ was considered statistically significant. We estimated that a sample size of 16 participants per group would be required to achieve $80 \%$ power to detect a $10^{\circ}$ difference in the aggregated angle for the two groups, assuming an overall standard deviation of $10^{\circ}$, similar to what was observed in a previous study [35].

\section{Results}

Patient characteristics

The median age was 67.5 (62-76.5) and 68 (54.8-75.5) years in the control and CTS group, respectively. All the participants were female. The physical findings and 


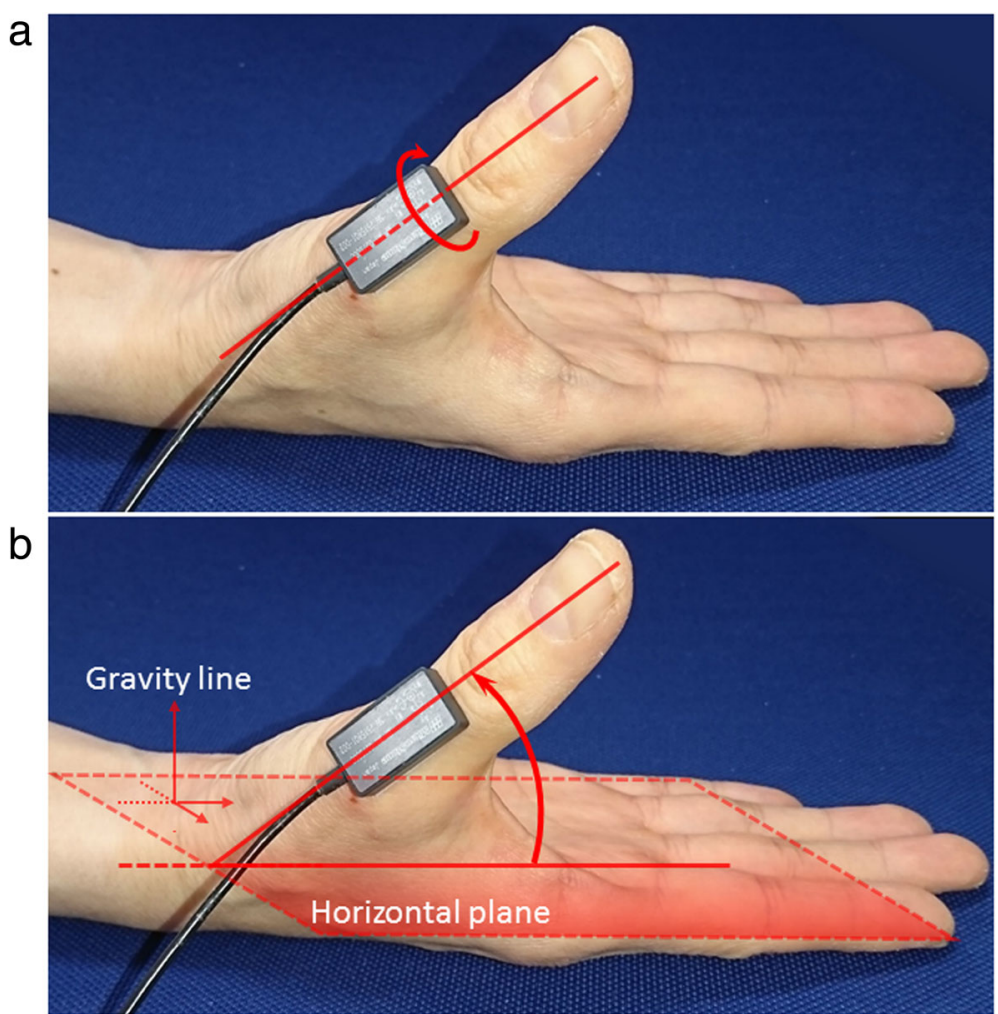

Fig. 2 The measured angle during opposition movement. a Pronation angle: the rotation angle around the longitudinal axis of the sensor. $\mathbf{b}$ Palmar abduction angle: the inclination angle of the longitudinal axis of the sensor to the horizontal plane

NCV tests in the CTS group are shown in Table 1. The physical examination showed moderate or severe thenar atrophy in 15 hands, and muscle strength less than good in 13 hands. In nearly all of the patients, CTS was classified as moderate or worse as per Padua's classification, and only one had mild CTS.

\section{Measurement data}

The median pronation angle on the first metacarpal was $31^{\circ}$ in the control group and $20^{\circ}$ in the CTS group. Median

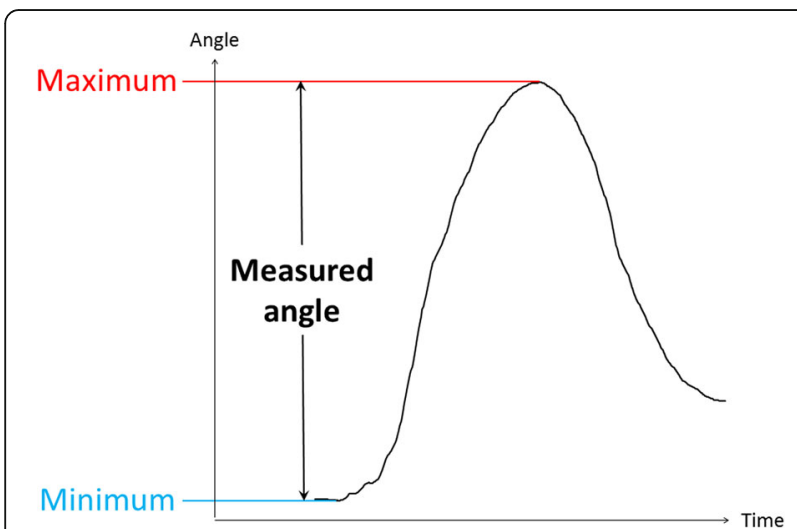

Fig. 3 The measured angle. Subtracting the minimum value from the maximum value of the obtained graph pronation angle on the phalanx was $21.5^{\circ}$ in the control group and $23^{\circ}$ in the CTS group. The median palmar abduction angle on the first metacarpal was $25^{\circ}$ in the control group and $18^{\circ}$ in the CTS group. The median palmar abduction angle on the phalanx was $55^{\circ}$ in the control group and $43^{\circ}$ in the CTS group (Table 2). The pronation angle of the metacarpal bone and the palmar abduction angle of the metacarpal bone and phalanx decreased significantly in patients in the CTS group. The average standard deviation of pronation angles of the metacarpal bone and phalanx were $1.3^{\circ}$ and $2.4^{\circ}$ respectively, and palmar abduction angles of the metacarpal bone and phalanx were $1.3^{\circ}$ and $1.9^{\circ}$ respectively. The $\mathrm{CV}$ of the pronation angles of the metacarpal bone and phalanx were 0.051 and 0.1 , and the palmar abduction angles of the metacarpal bone and phalanx were 0.059 and 0.04 respectively (Table 2 ).

We obtained transition graphs of the measured angles (Fig. 4). Most of the graphs of the pronation angle of phalanx showed a peak near the palmar abduction position during the opposition movement. However, the pronation angle of the metacarpal bone of 19 thumbs in the CTS group and 17 in the control group peaked when the thumb was in the full flexion position. Moreover, in all hands, the pronation angle peaked later than the palmar abduction angle did. The actual measurement time per participant was less than $10 \mathrm{~min}$. 
Table 1 Data of physical findings and NCV tests in the CTS group

\begin{tabular}{ll} 
group & CTS $(n=27)$ \\
\hline Thenar atrophy & 12 \\
Absent & 0 \\
Mild & 8 \\
Moderate & 7 \\
Severe & \\
Opposition MMT & 8 \\
5 (normal) & 6 \\
4 (good) & 10 \\
3 (fair) & 2 \\
2 (poor) & 1 \\
1 (trace) & 0 \\
0 (zero) & \\
Padua's classification & \\
Normal & 0 \\
Minimal & 0 \\
Mild & 1 \\
Moderate & 16 \\
Severe & 6 \\
Extreme & \\
\hline
\end{tabular}

NCV nerve conduction velocity, CTS carpal tunnel syndrome, MMT manual muscle test

\section{Discussion}

First, we investigated the reliability of measuring the thumb pronation and palmar abduction angles using a small sensor with a three-axis gyroscope and accelerometer. Previous studies have evaluated the pronation angle of the first metacarpal bone using $\mathrm{CT}$ in healthy volunteers and yielded various values for the average pronation angle. Cheema et al. and Kimura et al. reported that the pronation angles were $56^{\circ}$ and $57^{\circ}$ respectively $[36,37]$. We considered that the researchers only evaluated the thumb pronation, which was projected into two dimensions using $\mathrm{CT}$ imaging; therefore, the thumb pronation angle was overestimated as

Table 2 The range of motion during opposition movement

\begin{tabular}{|c|c|c|c|c|}
\hline & Control $(n=32)$ & CTS $(n=27)$ & $P$ value & CV \\
\hline \multicolumn{5}{|l|}{ Pronation $\left(^{\circ}\right)$} \\
\hline Metacarpal bone & $31(22.8-36.3)$ & $20(16.5-24.5)$ & $<0.001$ & 0.051 \\
\hline Phalanx & $21.5(15.3-30)$ & $23(23.5-33.5)$ & 0.76 & 0.1 \\
\hline \multicolumn{5}{|l|}{ Palmar abduction $\left({ }^{\circ}\right)$} \\
\hline Metacarpal bone & $25(21.8-29.3)$ & $18(13.5-24)$ & 0.004 & 0.059 \\
\hline Phalanx & $55(46.5-62.3)$ & $43(33-49)$ & $<0.001$ & 0.04 \\
\hline
\end{tabular}

Data are presented as the median (IQR). Statistical significance was determined with the Mann-Whitney $U$ test

CTS carpal tunnel syndrome, IQR interquartile range, $C V$ coefficient of variation the palmar abduction angle became closer to $90^{\circ}$. By contrast, Goto et al. and Kawanishi et al. reported that the pronation angle was $14.8^{\circ}$ and $22.3^{\circ}$ respectively using three-dimensional evaluation method [38, 39]. However, since the former showed the angle from the adduction position to the full flexion position as the pronation angle, it is reasonable that the numerical value becomes lower than ours. Moreover, their report had only one participant. The latter evaluated the differences from the radial abduction position to the full flexion position as the pronation angle using not dynamic CT but the static one. Therefore, it is reasonable that they underestimated the maximum pronation angles of the participants whose thumb pronation angle became maximum slightly later than the palmar abduction position. Moreover, most classical studies showed that the arc of pronation of the first metacarpal bone was less than $30^{\circ}$ [40].

Meanwhile, there are many reports of $\mathrm{CV}$ measurement of the range of motion of finger and wrist previously. Most of these were about 0.05-0.06 using the gyroscope, optical motion capture, and goniometer [41-43], and almost all the results of our study were similar values.

Hence, we considered that our method to measure the thumb pronation three-dimensionally using a gyroscope is sufficiently reliable.

We believe that measuring thumb pronation angle using a gyroscope has many advantages. Kapandji scores [44] are widely used to evaluate thumb opposition in clinical practice $[20,45-52]$. However, it is not an accurate quantitative evaluation method but only a numerical categorized method; moreover, there were reports that almost all healthy subject and even CTS patients with thenar atrophy were able to obtain 9 or 10 points of this score $[22,53]$. Although three-dimensional CT was able to measure the angle accurately, it is costly, requires time and effort, and above all, it is very invasive. Optical motion capture systems are dynamic, three-dimensional, and non-invasive but complicated and also require time, effort, and, moreover, a large specialized apparatus. In contrast, a gyroscope is compact, wearable, economical, easy to handle $[30,31]$, three-dimensional, and non-invasive.

Second, we were able to measure the pronation as well as the palmar abduction angles of the thumb during opposition movements in patients in the control and CTS groups. As expected, there was a significant decrease in the pronation angle of the metacarpal bone and palmar abduction angle of the metacarpal bone and phalanx in patients in the CTS group.

There is only one report of the comparison of thumb pronation angle along the three-dimensionally moving bone axis between healthy subjects and CTS patients 

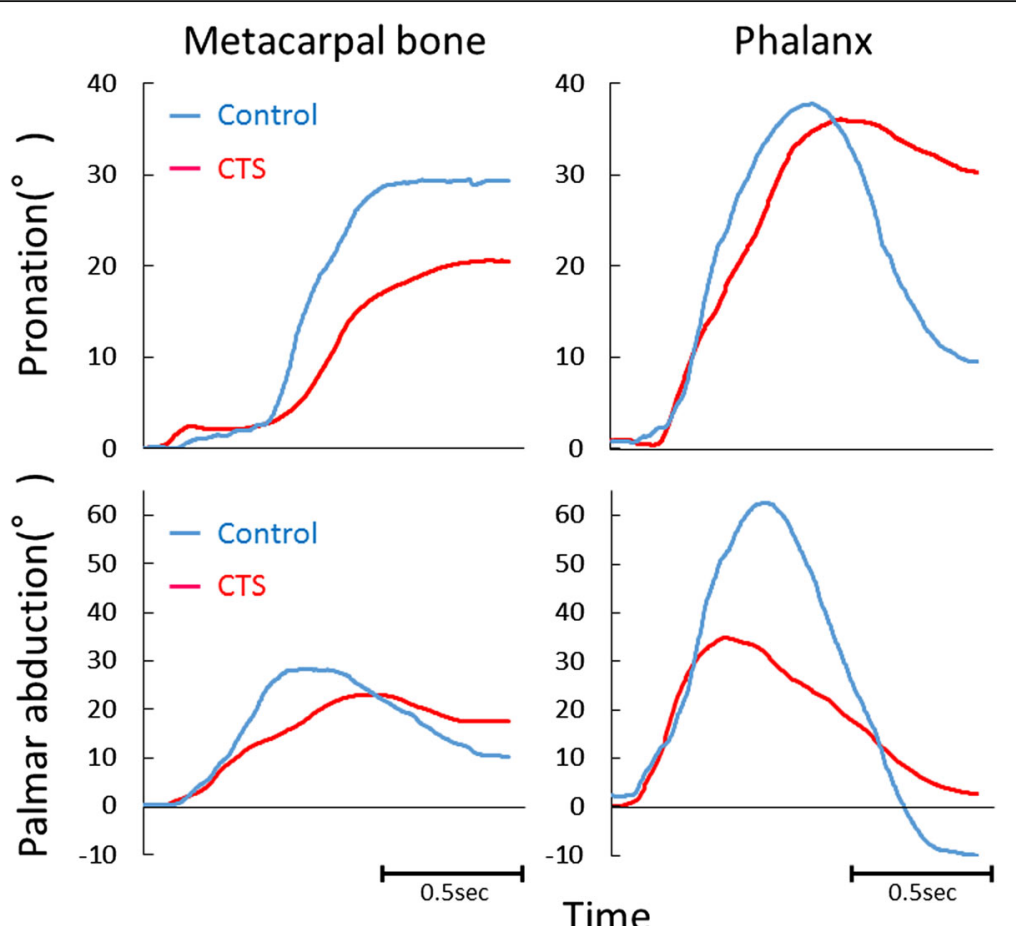

Fig. 4 Four representative examples of transition graphs. The measured angles in the CTS (red) and control (blue) groups. Upper: pronation angle; lower: palmar abduction angle; left: metacarpal bone; right: phalanx. CTS: carpal tunnel syndrome

using an optical motion capture system [35]. However, the pronation angle in the CTS group decreased, but not significantly. Conversely, our study showed a significant decrease in this angle in patients with CTS. We considered that the discrepancy in these results was because of the difference in the severity of CTS between patients in the previous study and those in ours. In our study, we recruited only CTS patients with thenar atrophy before they underwent surgery, and the disease in almost all of these patients was classified as moderate or worse according to Padua's classification. By contrast, it is reasonable to assume that the CTS group in the previous study included patients with minimal or mild CTS or patients without a motor disorder. This is because previous reports included (i) only patients with abnormal NCV values, while the threshold was not mentioned and (ii) those with a score of at least 1.5 on the Severity Scale [54]. Furthermore, our study had more than twice the number of cases that this previous study did. These differences in the characteristics of participants may account for the differences in results.

Interestingly, in this study, we also demonstrated a decrease in the angle on metacarpal bone. As CTS causes atrophies of the abductor pollicis brevis muscle and opponens pollicis muscle [55], the result is anatomically feasible. Furthermore, the fact that this method was able to measure the pronation of the metacarpal bone may suggest the applicability of the method to diseases other than CTS, such as osteoarthritis of the CM.

The advancement and importance of our method are anchored on two points. First, by miniaturization of gyroscopes, we succeeded in measuring the thumb pronation angle, which had not been previously measured with a gyroscope. Second, our method allowed the detection of the pronation angle impairment due to CTS easily, non-invasively, and three-dimensionally and represented it numerically.

This study has several limitations. First, it is possible that stretching of the skin while the sensor was applied affected the results. However, this effect should have reduced the measured angle, thereby making it more difficult to obtain any significant outcome. Second, we did not measure the angles of the metacarpal bone and phalanx simultaneously; therefore, we were not able to evaluate the phalanx angle independently. Third, six patients who used canes or walkers were included because the control group consisted of patients with hip osteoarthritis rather than healthy volunteers. Thus, the mechanical effect of a T cane on the first web may have affected the results.

We plan to perform further studies involving simultaneous measurement of the first metacarpal bone and phalanx of the participants and to apply this measurement technique in patients with mild CTS and those with other diseases such as osteoarthritis of the CM. 
Furthermore, we plan to use this method to evaluate the differences in the pre- and post-opponensplasty pronation angles. In the future, we intend to establish this method as a diagnostic tool for CTS clinically.

\section{Conclusion}

We were able to apply a gyroscope as a new measurement method of pronation and palmar abduction angles of thumb. It was easy, quick, and non-invasive. Furthermore, we were able to demonstrate the significant decrease in the pronation angle of the metacarpal bone and palmar abduction angle of the metacarpal bone and phalanx in patients in the CTS group using the method.

\section{Abbreviations}

CM: Carpometacarpal; CT: Computed tomography; CTS: Carpal tunnel syndrome; CV: Coefficient of variation; MP: Metacarpophalangeal; NCV: Nerve conduction velocity

\section{Acknowledgements}

We would like to thank Editage (www.editage.jp) for English-language editing.

\section{Funding}

The study was funded by Hitachi, Ltd.

\section{Availability of data and materials}

The datasets used and/or analyzed during the current study are available from the corresponding author on reasonable request.

\section{Authors' contributions}

TK performed all experiments and analyses and prepared the first draft of the paper. KF designed the study, collected patient data, and supervised the project. He is the guarantor. AN and TM collected the patients' data and provided advice about the experimental conditions. TS and AO provided advice about the experimental conditions. All authors read and approved the final manuscript.

\section{Ethics approval and consent to participate}

This comparative study was approved by the Tokyo Medical and Dental University institutional review board (M2017-123), and all participants provided written informed consent.

\section{Consent for publication}

Not applicable.

\section{Competing interests}

The authors declare that they have no competing interests.

\section{Publisher's Note}

Springer Nature remains neutral with regard to jurisdictional claims in published maps and institutional affiliations.

\section{Author details \\ 'Department of Orthopaedic and Spinal Surgery, Graduate School of Medical and Dental Sciences, Tokyo Medical and Dental University, 1-4-5, Yushima, Bunkyo-ku, Tokyo 113-8519, Japan. ${ }^{2}$ Department of Functional Joint Anatomy, Graduate School of Medical and Dental Sciences, Tokyo Medical and Dental University, 1-4-5, Yushima, Bunkyo-ku, Tokyo 113-8519, Japan.}

Received: 11 July 2018 Accepted: 6 November 2018 Published online: 16 November 2018

\section{References}

1. Aubin PM, Sallum H, Walsh C, Stirling L, Correia A. A pediatric robotic thumb exoskeleton for at-home rehabilitation: the Isolated Orthosis for
Thumb Actuation (IOTA). In: IEEE International Conference on Rehabilitation Robotics: [proceedings], vol. 2013; 2013. p. 6650500.

2. Berger AJ, Meals RA. Management of osteoarthrosis of the thumb joints. J Hand Surg Am. 2015;40:843-50.

3. Kurtzman LC, Stern PJ, Yakuboff KP. Reconstruction of the burned thumb. Hand Clin. 1992:8:107-19.

4. Swanson $A B$, Hagert CG, Swanson GD. Evaluation of impairment of hand function. J Hand Surg Am. 1983;8:709-22.

5. Winzeler S, Rosenstein BD. Occupational injury and illness of the thumb. Causes and solutions. AAOHN J. 1996;44:487-92.

6. Edmunds JO. Current concepts of the anatomy of the thumb trapeziometacarpal joint. J Hand Surg Am. 2011;36:170-82.

7. Olafsdottir $\mathrm{H}$, Zatsiorsky VM, Latash ML. Is the thumb a fifth finger? A study of digit interaction during force production tasks. Exp Brain Res. 2005:160:203-13.

8. Lee DH, Oakes JE, Ferlic RJ. Tendon transfers for thumb opposition: a biomechanical study of pulley location and two insertion sites. J Hand Surg Am. 2003;28:1002-8.

9. Plata Bello J, Modrono C, Marcano F, Gonzalez-Mora JL. The effect of motor familiarity during simple finger opposition tasks. Brain Imaging Behav, 2015:9:828-38.

10. Tas $\mathrm{S}, \mathrm{Top} \mathrm{H}$. Bilateral congenital absence of the opponens pollicis muscle: a case report. Hand (N Y). 2015;10:143-6.

11. Geere J, Chester R, Kale S, Jerosch-Herold C. Power grip, pinch grip, manual muscle testing or thenar atrophy - which should be assessed as a motor outcome after carpal tunnel decompression? A systematic review. BMC Musculoskelet Disord. 2007;8:114.

12. Li T, Hua XY, Zheng MX, Wang WW, Xu JG, Gu YD, et al. Different cerebral plasticity of intrinsic and extrinsic hand muscles after peripheral neurotization in a patient with brachial plexus injury: a TMS and fMRI study. Neurosci Lett. 2015;604:140-4.

13. Foucher G, Malizos C, Sammut D, Braun FM, Michon J. Primary palmaris longus transfer as an opponensplasty in carpal tunnel release. A series of 73 cases. J Hand Surg (Edinb.). 1991;16:56-60.

14. Gelberman RH, Pfeffer GB, Galbraith RT, Szabo RM, Rydevik B, Dimick M. Results of treatment of severe carpal-tunnel syndrome without internal neurolysis of the median nerve. J Bone Joint Surg Am. 1987;69:896-903.

15. Kaymak B, Inanici F, Ozcakar L, Cetin A, Akinci A, Hascelik Z. Hand strengths in carpal tunnel syndrome. J Hand Surg Eur Vol. 2008;33:327-31.

16. Nolan WB 3rd, Alkaitis D, Glickel SZ, Snow S. Results of treatment of severe carpal tunnel syndrome. J Hand Surg Am. 1992;17:1020-3.

17. Bertelli JA, Soldado F, Rodrigues-Baeza A, Ghizoni MF. Transfer of the motor branch of the abductor digiti quinti for thenar muscle reinnervation in high median nerve injuries. J Hand Surg Am. 2018;43:8-15.

18. Kato N, Yoshizawa T, Sakai H. Simultaneous modified Camitz opponensplasty using a pulley at the radial side of the flexor retinaculum in severe carpal tunnel syndrome. J Hand Surg Eur Vol. 2014;39:632-6.

19. Park IJ, Kim HM, Lee SU, Lee JY, Jeong C. Opponensplasty using palmaris longus tendon and flexor retinaculum pulley in patients with severe carpal tunnel syndrome. Arch Orthop Trauma Surg. 2010;130:829-34.

20. Poy-Gual C, Puente-Alonso C, Cano-Rodriguez G. Modified Camitz opponensplasty for treatment of severe carpal tunnel syndrome. J Hand Surg Eur Vol. 2018. https://doi.org/10.1177/1753193418787666.

21. Rymer B, Thomas PB. The Camitz transfer and its modifications: a review. J Hand Surg Eur Vol. 2016:41:632-7.

22. Dilokhuttakarn T, Naito K, Kinoshita M, Sugiyama Y, Goto K, Iwase Y, et al. Evaluation of thenar muscles by MRI in carpal tunnel syndrome. Exp Ther Med. 2017;14:2025-30

23. Allseits E, Agrawal V, Lucarevic J, Gailey R, Gaunaurd I, Bennett C. A practical step length algorithm using lower limb angular velocities. J Biomech. 2018;66:137-44.

24. Allseits E, Kim K, Bennett C, Gailey R, Gaunaurd I, Agrawal V. A novel method for estimating knee angle using two leg-mounted gyroscopes for continuous monitoring with mobile health devices. Sensors (Basel). 2018;18:2759.

25. Holl S, Blum A, Gosheger G, Dieckmann R, Winter C, Rosenbaum D. Clinical outcome and physical activity measured with StepWatch 3 Activity Monitor after minimally invasive total hip arthroplasty. J Orthop Surg Res. 2018;13:148.

26. Staab W, Hottowitz R, Sohns C, Sohns JM, Gilbert F, Menke J, et al. Accelerometer and gyroscope based gait analysis using spectral analysis of patients with osteoarthritis of the knee. J Phys Ther Sci. 2014;26:997-1002. 
27. Salarian A, Russmann H, Wider C, Burkhard PR, Vingerhoets FJ, Aminian K. Quantification of tremor and bradykinesia in Parkinson's disease using a novel ambulatory monitoring system. IEEE Trans Biomed Eng. 2007:54:313-22.

28. Summa S, Tosi J, Taffoni F, Di Biase L, Marano M, Rizzo AC, et al. Assessing bradykinesia in Parkinson's disease using gyroscope signals. In: IEEE International Conference on Rehabilitation Robotics : [proceedings], vol. 2017; 2017. p. 1556-61.

29. Le Moing AG, Seferian AM, Moraux A, Annoussamy M, Dorveaux E, Gasnie $E$, et al. A movement monitor based on magneto-inertial sensors for nonambulant patients with Duchenne muscular dystrophy: a pilot study in controlled environment. PLoS One. 2016;11:e0156696.

30. Boonstra MC, van der Slikke RM, Keijsers NL, van Lummel RC, de Waal Malefijt $\mathrm{MC}$, Verdonschot $\mathrm{N}$. The accuracy of measuring the kinematics of rising from a chair with accelerometers and gyroscopes. J Biomech. 2006;39:354-8.

31. Camomilla V, Bergamini E, Fantozzi S, Vannozzi G. Trends supporting the infield use of wearable inertial sensors for sport performance evaluation: a systematic review. Sensors (Basel). 2018;18:873.

32. Padua L, LoMonaco M, Gregori B, Valente EM, Padua R, Tonali $P$. Neurophysiological classification and sensitivity in 500 carpal tunnel syndrome hands. Acta Neurol Scand. 1997;96:211-7.

33. Bunnell S. Peripheral Nerve Injuries by the Nerve Injuries Committee of the Medical Research Council. Edited by H. J. Seddon. (Privy Council. Medica Research Council Special Report Series. No. 282.) London, Her Majesty's Stationery Office, 1954. 2 pounds, 15 shillings. JBJS 1955;37:895.

34. Doi T, Makizako H, Shimada H, Yoshida D, Ito K, Kato T, et al. Brain atrophy and trunk stability during dual-task walking among older adults. J Gerontol A Biol Sci Med Sci. 2012;67:790-5.

35. Marquardt TL, Nataraj R, Evans PJ, Seitz WH Jr, Li ZM. Carpal tunnel syndrome impairs thumb opposition and circumduction motion. Clin Orthop Relat Res. 2014;472:2526-33.

36. Cheema TA, Cheema NI, Tayyab R, Firoozbakhsh K. Measurement of rotation of the first metacarpal during opposition using computed tomography. J Hand Surg Am. 2006;31:76-9.

37. Kimura T, Takai H, Azuma T, Sairyo K. Motion analysis of the trapeziometacarpal joint using three-dimensional computed tomography. J Hand Surg Asian Pac Vol. 2016;21:78-84

38. Goto A, Leng S, Sugamoto K, Cooney WP 3rd, Kakar S, Zhao K. In vivo pilot study evaluating the thumb carpometacarpal joint during circumduction. Clin Orthop Relat Res. 2014;472:1106-13.

39. Kawanishi Y, Oka K, Tanaka H, Okada K, Sugamoto K, Murase T. In vivo 3dimensional kinematics of thumb carpometacarpal joint during thumb opposition. J Hand Surg Am. 2018;43:182 e1-.e7.

40. Coert JH, van Dijke HG, Hovius SE, Snijders CJ, Meek MF. Quantifying thumb rotation during circumduction utilizing a video technique. J Orthop Res. 2003;21:1151-5.

41. Ancillao A, Savastano B, Galli M, Albertini G. Three dimensional motion capture applied to violin playing: a study on feasibility and characterization of the motor strategy. Comput Methods Prog Biomed. 2017;149:19-27.

42. Lewis $E$, Fors $L$, Tharion WJ. Interrater and intrarater reliability of finger goniometric measurements. Am J Occup Ther. 2010;64:555-61.

43. O'Flynn B, Sanchez JT, Tedesco S, Downes B, Connolly J, Condell J, et al. Novel smart glove technology as a biomechanical monitoring tool. Sens Transducers. 2015:193:23-32.

44. Kapandji A. Clinical test of apposition and counter-apposition of the thumb. Ann Chir Main. 1986:5:67-73.

45. Durban CM, Antolin B, Sau CY, Li SW, Ip WY. Thumb function and electromyography result after modified Camitz tendon transfer. J Hand Surg Asian Pac Vol. 2017;22:275-80.

46. Goubier JN, Teboul F. Management of hand palsies in isolated C7 to T1 or C8, T1 root avulsions. Tech Hand Up Extrem Surg. 2008;12:156-60.

47. Hutchinson DT, Sueoka S, Wang AA, Tyser AR, Papi-Baker K, Kazmers $\mathrm{NH}$. A prospective, randomized trial of mobilization protocols following ligament reconstruction and tendon interposition. J Bone Joint Surg Am. 2018;100:1275-80.

48. Lefevre-Colau MM, Poiraudeau S, Oberlin C, Demaille S, Fermanian J, Rannou F, et al. Reliability, validity, and responsiveness of the modified Kapandji index for assessment of functional mobility of the rheumatoid hand. Arch Phys Med Rehabil. 2003:84:1032-8.

49. Lemoine S, Wavreille G, Alnot JY, Fontaine C, Chantelot C. Second generation GUEPAR total arthroplasty of the thumb basal joint: 50 months follow-up in 84 cases. Orthop Traumatol Surg Res. 2009;95:63-9.
50. Pradier JP, Oberlin C, Bey E. Acute deep hand burns covered by a pocket flapgraft: long-term outcome based on nine cases. J Burns Wounds. 2007;6:e1.

51. van Rijn J, Gosens T. A cemented surface replacement prosthesis in the basal thumb joint. J Hand Surg Am. 2010;35:572-9.

52. Zhang YX, Wang D, Zhang Y, Ong YS, Follmar KE, Tahernia AH, et al. Triple chimeric flap based on anterior tibial vessels for reconstruction of severe traumatic injuries of the hand with thumb loss. Plast Reconstr Surg. 2009; 123:268-75.

53. Barakat MJ, Field J, Taylor J. The range of movement of the thumb. Hand ( $N$ Y). 2013;8:179-82

54. Levine DW, Simmons BP, Koris MJ, Daltroy LH, Hohl GG, Fossel AH, et al. A self-administered questionnaire for the assessment of severity of symptoms and functional status in carpal tunnel syndrome. J Bone Joint Surg Am. 1993;75:1585-92.

55. Rhoades CE, Mowery CA, Gelberman RH. Results of internal neurolysis of the median nerve for severe carpal-tunnel syndrome. J Bone Joint Surg Am. 1985;67:253-6.
Ready to submit your research? Choose BMC and benefit from:

- fast, convenient online submission

- thorough peer review by experienced researchers in your field

- rapid publication on acceptance

- support for research data, including large and complex data types

- gold Open Access which fosters wider collaboration and increased citations

- maximum visibility for your research: over $100 \mathrm{M}$ website views per year

At $\mathrm{BMC}$, research is always in progress.

Learn more biomedcentral.com/submissions 